Вамиева 3.С. ${ }^{1}$, Грацианская С.Е. ${ }^{1}$, Мартынюк Т.В. ${ }^{1,2}$

${ }^{1}$ ФГБУ «Национальный медицинский исследовательский центр кардиологии» МинзАрава РФ,

«Научно-исследовательский институт клинической кардиологии им. А.А. Мясникова», Москва, Россия

2 «Российский национальный исследовательский медицинский университет имени Н. И. Пирогова», Москва, Россия

\title{
ПРИМЕНЕНИЕ РИОЦИГУАТА
}

\section{ААЯ АЕЧЕНИЯ ПАЦИЕНТОВ С ХРОНИЧЕСКОЙ

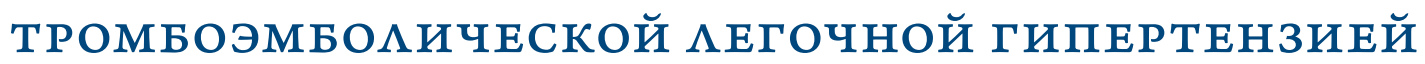

\begin{abstract}
Хроническая тромбоэмболическая мегочная гипертензия (ХТЭАГ) - прекапимлярная форма мегочной гипертензии, при которой хроническая обструкция крупных и среАних ветвей мегочных артерий, а также вторичные изменения микроциркуляторного русла мегких привоАят к прогрессирующему повышению мегочного сосуАистого сопротивления и Аавцения в Аегочной артерии с развитием тяжелой Аисфункции правых отделов серАца и сердечной недостаточности. Аегочная

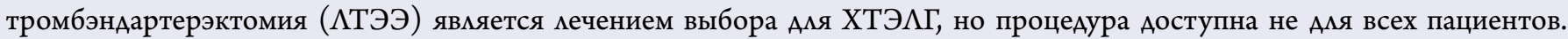
Несмотря на то, что оперативное мечение, выполняемое в условиях центров с передовым опытом, в целом Аемонстрирует хорошие результаты, до 40\% пациентов являются технически неоперабельными, или АТЭЭ сопряжена с высоким риском осложнений. В настоящее время в качестве препарата первой Аинии Аля терапии неоперабельных и резидуальных форм ХТЭАГ рассматривается еАинственный официально оАобренный препарат из класса стимуляторов растворимой гуанилатциклазы риоцигуат. ВнеАрение риоцигуата в клиническую практику можно назвать настоящим прорывом в мечении пациентов с ХТЭАГ, которым невозможно провести $\Lambda$ ТЭЭ, или у которых после оперативного мечения наблюАается рецидив или персистирующая ХТЭАГ.
\end{abstract}

Ключевые слова

Хроническая тромбоэмболическая мегочная гипертензия; мегочная тромбэндартерэктомия, риоцигуат

Амя циитирования

Valieva Z.S., Gratsianskaya S.E., Martynyuk T.V. The soluble guanylate cyclase stimulator riociguat is the first-line therapy for chronic thromboembolic pulmonary hypertension patients. Kardiologiia. 2020;60(8):115-123. [Russian: Валиева 3.С., Грацианская С.Е., Мартынюк Т.В. Применение риоцигуата Аля мечения пациентов с хронической тромбоэмболической мегочной гипертензией. КарАиомогия. 2020;60(8):115-123]

Автор для переписки Валиева Зарина Солтановна. E-mail: v.zarina.v@gmail.com

\section{Актуамьные вопросы хронической} тромбоэмболической мегочной гипертензии

Хроническая тромбоэмболическая мегочная гипертензия (ХТЭАГ) - прекапимлярная форма мегочной гипертензии $(\Lambda \Gamma)$, при которой хроническая обструкция крупных и среАних ветвей мегочных артерий $(\Lambda A)$, а также вторичные изменения микроциркуляторного русла мегких, привоАят к прогрессирующему повышению мегочного сосуАистого сопротивления $(\Lambda \mathrm{CC})$ и Аавления в $\Lambda$ A $(A \Lambda \mathrm{A})$ с развитием тяжелой Аисфункции правых отАелов серАца и серАечной недостаточности $[1-3]$.

Аиагноз устанавливается при наличии следующих критериев, выявленных, как минимум, через 3 месяца после начала эффективной антикоагулянтной терапии, что необходимо аля Аифференциальной диагностики ХТЭАГ от поАострой тромбоэмболии $\Lambda$ А (ТЭ$\Lambda \mathrm{A})$ : среАнее $A \Lambda \mathrm{A}($ срА $\Lambda \mathrm{A}) \geq 25$ мм рт. ст. при Аавмении заклинивания $\Lambda \mathrm{A} \leq 15$ мм рт. ст.; как минимум один сегментарный дефект перфузии по Аанным вентимяционно-перфузионной сцинтиграфии мегких или обструкция $\Lambda$ А по Аанным компьютерной томографии-ангиографии или семективной ангиопумьмонографии; у ряда пациен- тов, особенно с оАносторонней оккмюзией $\Lambda$ А, могут иметь место нормальные показатели гемодинамики мамого круга кровообращения в покое, несмотря на наличие симптомов заболевания. Эту группу пациентов слеАует расценивать как пациентов с ХТЭ $\Lambda$ с соответствующей тактикой [4].

Точные эпидемиологические Аанные о распространенности ХТЭАГ как в нашей стране, так и в мире в настоящее время отсутствуют. Согласно большинству работ, ХТЭАГ явмяется реАким заболеванием, которое наблюдается с частотой 3-30 случаев на 1 млн общей попумяции [5]. По мере изучения проблемы ХТЭАГ Аанные эпидемиологии тоже изменяются. Так, в проспективном когортном исследовании в Великобритании, проведенном Condliffe R. и соавт. в одном из пяти специализированных центров $\Lambda$, в 2005 г. показало заболеваемость на уровне 1,75 скучаев на 1 млн насемения [1]. Согласно Европейским рекомендациям 2015 г., заболеваемость ХТЭАГ составмяет примерно 5 случаев на 1 млн попумяции в гоА [3]. Но распространенность ХТЭАГ может быть выше, чем предполагалось ранее. По Аанным Pepke-Zaba J. и соавт. Аоля ХТЭАГ в структуре вновь Аиагностированных скучаев $\Lambda Г$ 14\% [6]. В 2015 году забо- 
меваемость ХТЭАГ в США и Европе Аостигала 50 случаев на 1 млн насемения [7].

Согласно обновленным рекомендациям от 2018 г. по результатам консенсусной конференции в Кельне заболеваемость ХТЭАГ состав яет 4 случая на 1 млн попумяции в год. Также было показано, что обследование пациентов с персистирующими симптомами после острой ТЭАА приводит к Аиагнозу ХТЭАГ/хронической тромбоэмболической болезни в 8,5\% скучаев [8]. Известно, что до $75 \%$ пациентов с ХТЭ $\Lambda Г$ не имеют ТЭ $\Lambda$ в анамнезе, что также затрудняет своевременную постановку диагноза [6].

Цели успешного мечения Аостигаются только в том случае, если правильный диагноз установлен на ранних стадиях заболевания и своевременно начато соответствующее мечение. ХТЭАГ явмяется уникальной формой $\Lambda \Gamma$, поскольку она потенциально измечима с помощью хирургического мечения. Аегочная тромбэндартерэктомия ( $\Lambda$ ТЭЭ) явмяется мечением выбора Аля ХТЭ $\Lambda Г$, но процедура доступна не Аля всех пациентов. Решение о хирургической тактике ведения пациента с ХТЭАГ или патогенетической медикаментозной терапии должно приниматься экспертным центром на основе межАисциплинарного обсужАения среди карАиологов, радиологов, хирургов-экспертов. Около 36,6\% пациентов признаются неоперабельными из-за дистального поражения $\Lambda$ A, когАа крайне высок риск рецидива $\Lambda$ в раннем послеоперационном периоде; при выраженной дисфункции правого желудочка; тяжелых заболеваниях мегких, способствующих нарушению вентиляционно-перфузи- онного соотношения в послеоперационном периоде; риске развития посткапимлярной $\Lambda$ в послеоперационном периоде или полиорганной недостаточности; риске кровотечения в послеоперационном периоде; наличии Аругих противопоказаний к проведению искусственного кровообращения с циркумяторным арестом; отказе пациента от операции $[6,9]$. По Аругим Аанным, каждый третий пациент с ХТЭ $\Lambda Г$ неоперабемен, и у кажАого второго пациента сохраняется $\Lambda \Gamma$ после операции $[7,10]$. Медикаментозная терапия показана пациентам с технически неоперабельной формой заболевания. Пациенты с персистирующей или рецидивирующей $\Lambda$ после выполненной операции $\Lambda$ ТЭЭ могут также явмяться кандиАатами Амя медикаментозного мечения [4].

\section{Риоцигуат - первый преАставитель} инновационного кАасса стимуяяторов растворимой гуаниматцикмазы

Риоцигуат имеет Авойной механизм Аействия, так, с оАной стороны, он напрямую, независимо от уровня эндогенного оксида азота (NO), стимулирует растворимую гуаниматцикмазу (рГЦ), а с Аругой - повышает чувствительность рГЦ к эндогенному NO [11]. За счет повышения уровня циклического гуанозинмонофосфата (цГМФ) риоцигуат приводит к вазодилатации, подавлению пролиферации и оказывает антифиброзный и противовоспалительный эффект. Риоцигуат восстанавливает метаболический путь NO - рГЦ - цГМФ и вызывает увеличение продукции цГМФ, который играет важную роль в регуляции процессов, влияющих на тонус сосудов, пролифера-

Рисунок 1. Путь NO в регумяции функции кегочных сосудов (аАаптировано из [12])

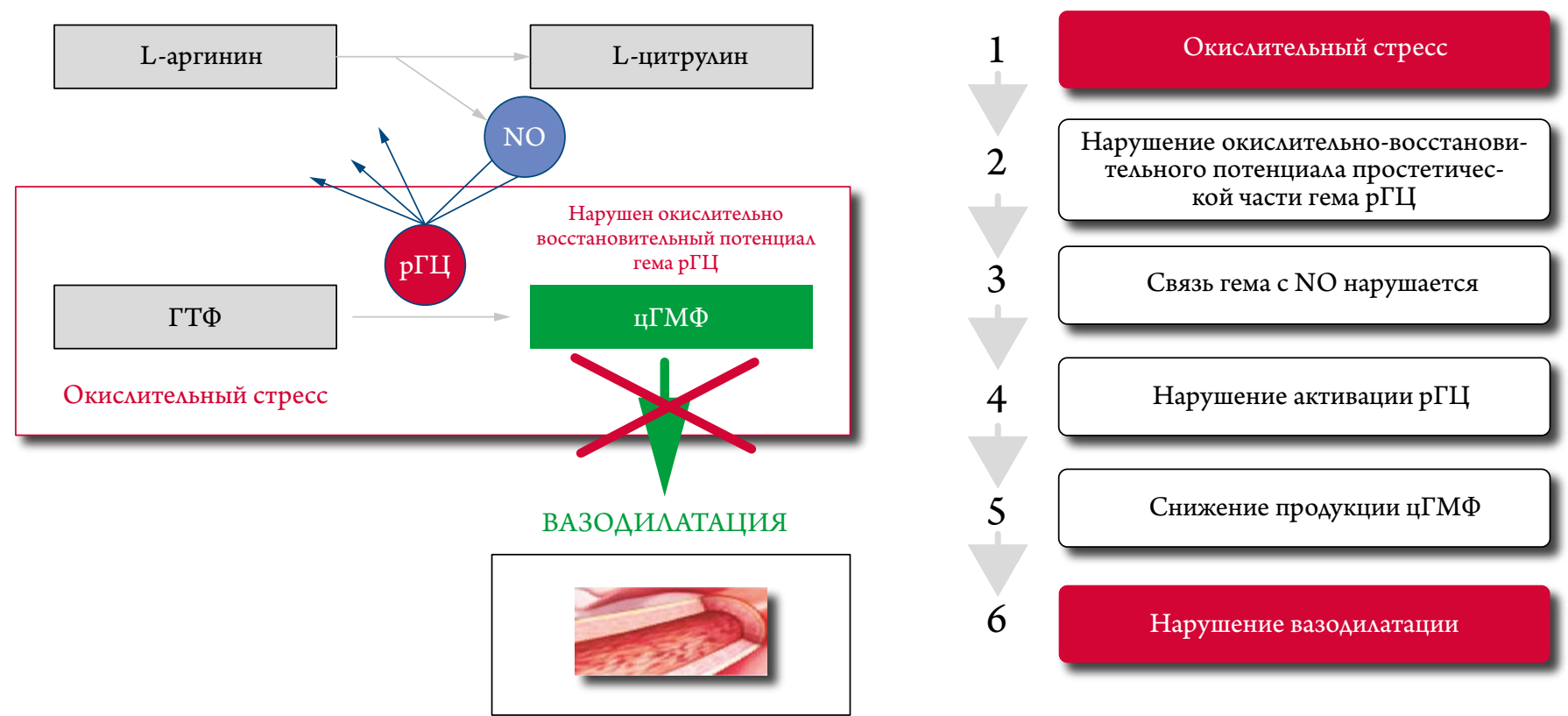

ГТФ - гуанозинтрифосфат; $N O$ - оксид азота; рГЦ - растворимая гуанилатииклаза; иГМФ - ииклический гуанозинмонофосфат.

При $\Lambda$ нарушение процесса вазодияатации может набюдаться даже при достаточном количестве эндогенного NO. 
цию, фиброз и воспаление. КАасс стимуляторов рГЦ был разработан, в том числе с целью повышения биодоступности NO в условиях инактивации NO и нарушений окислительно-восстановительного статуса рГЦ (рис. 1) [12].

Наличие Авойного механизма Аействия явмяется залогом более выраженного эффекта риоцигуата по сравнению с ингибиторами фосфодиэстеразы типа 5 (ИФАЭ-5). Терапевтическое действие ИФАЭ-5 ограничивается низким уровнем цГМФ, а также зависит от исходной концентрации NO, которая снижена у пациентов с мегочной артериальной гипертензией $(\Lambda А Г)$ и ХТЭАГ.

Алгоритм титрации риоцигуата заключается в приеме первоначальной дозы 1 мг 3 раза в сутки с Аальнейшим увеличением дозы на 0,5 мг 3 раза в сутки каждые 2 неАели Ао максимальной 2,5 мг 3 раза в сутки при систолическом артериальном Аавлении (АA) более 95 мм рт. ст. и при отсутствии симптомов артериальной гипотонии (согласно алгоритму титрации препарата, указанному в медицинской инструкции по применению препарата) [13].

\section{Риоцигуат при хронической тромбоэмболической мегочной гипертензии}

В настоящее время в качестве препарата первой минии Аля терапии неоперабельных и резилуальных форм ХТЭАГ рассматривается еАинственный официально одобренный препарат из класса стимукяторов рГЦ риоцигуат, что основано на доказательной базе рандомизированного клинического исследования CHЕST-1 и Алительного иссиедования CHEST-2 [3, 4, 14-19]. Рандомизированное плацебо-контролируемое исследование CHEST-1 исследование по оценке эффективности и безопасности кекарственной терапии у больных с неоперабельными и персистирующими/рецидивирующими формами ХТЭАГ, в котором были получены убедительные позитивные результаты. В исследование III фазы CHEST-1 бым включен 261 пациент. Ранее они не получали специфические препараты. Рандомизация осуществмялась в соотношении 2:1 Аля получения риоцигуата или плацебо. СреАний возраст пациентов составия $59 \pm 14$ мет, $66 \%$ из них - женщины, 71\% исследуемых -европеоидной расы. Большинство из пациентов имели II (31\%) или III (64\%) функциональный класс (ФК) (по классификации Всемирной организации зАравоохранения (ВО3) и неоперабельную форму ХТЭАГ (72\% пациентов). К 16-й неАеме наблюдения из исследования выбыли 18 пациентов. Стартовая Аоза риоцигуата составмяла 1 мг 3 раза в сутки. КажАые Аве недели в зависимости от уровня АА и симптоматики осуществмялась титрация дозы на 0,5 мг 3 раза в сутки до максимальной - 2,5 мг 3 раза в сутки. Изменения дистанции в тесте 6 минутной ходьбы (АТ6МХ) по сравнению с исходными Аанными к 16-й недеме яв- мялись первичной конечной точкой, а изменения $\Lambda$ СС, уровня $\mathrm{N}$-терминального пропептиАа натрийуретического гормона (NT-proBNP), ФК (BO3), времени до клинического ухудшения, оценка одышки по шкаме Борга, вариабельность качества жизни составмяли вторичные точки. Также изучали безопасность. АТ6МХ к 16-й неделе увеличилась в среднем на 39 м в группе риоцигуата по сравнению со снижением в среднем на 6 м в группе плацебо - средняя разница составмяла 46 м (95\% доверительный интервал (АИ) от 25 до 67 м; p<0,001). Риоцигуат продемонстрировал значительное снижение уровня NT-proBNP (плацебо-корригируемые средние значения -444 пг /ми, 95\% АИ от -843 Ао $-45, \mathrm{p}<0,0001)$ и улучшение ФК (ВО3) ( $\mathrm{p}=0,003)$. Статистически значимое снижение $\Lambda$ СС (-246 Аин ×схсм-5, 95\% АИ от -303 Ао -190, $\mathrm{p}<0,001)$ бымо выявмено в группе риоцигуата по сравнению с плацебо [15].

В целом 237 пациентов после завершения участия в исследовании CHEST-1 были включены в Алительное исследование CHEST-2. В течение первых 8 недель провоАилась «заслепленная» титрация препарата, в последующем осуществмялось открытие терапии. К первому году исследования CHEST-2 AT6МХ увеличилась Ао $+59 \pm 58$ м в группе пациентов, ранее принимавших риоцигуат $(\mathrm{n}=114),+37 \pm 69$ м у пациентов, ранее находившихся в группе плацебо $(\mathrm{n}=58)$, и $+51 \pm 62$ м в общей попумяции $(\mathrm{n}=172)$. В общей попумяции среАнее значение \pm стандартное откмонение (среднее \pm СО) АТ6МХ было $409 \pm 96$ м (n=172) к первому году наблюдения по сравнению с исходной $351 \pm 78$ м $(\mathrm{n}=237)$ [16]. К первому гоАу ФК (ВОЗ) улучшился/стабилизировался/ухудшился у 50/45/4\% пациентов соответственно в бывшей группе риоцигуата $(\mathrm{n}=117)$ и $39 / 59 / 2 \%$ соответственно в бывшей группе плацебо ( $\mathrm{n}=59), 47 / 50 / 3 \%$ - в общей

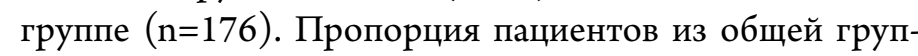
пы с ФК (ВОЗ) I/II/III/IV к первому году составила $14 / 54 / 31 / 1 \%(n=177)$ соответственно, по сравнению с исходными данными - $1 / 31 / 65 / 3 \%(n=236)$.

Непрерывное снижение уровня NT-proBNP в группе риоцигуата в исследовании CHEST-1 наблюАаиось к первому году исследования CHEST-2 и составимо $-375 \pm 1182$ ( $n=102)$. Пациенты из группы плацебо CHEST-1 показали выраженное снижение NT-proBNP на $-505 \pm 1591$ пг Хмл-1 $(n=47)$ после перевода на риоцигуат в исследовании CHEST-2 по сравнению с исходным уровнем $(\mathrm{n}=68)$. К концу первого года в общей популяции уровень NT-proBNP снизился на $-416 \pm 1321$ пгхмА ${ }^{-1}$ $(\mathrm{n}=149)$ в сравнении с исходным уровнем $(\mathrm{n}=204)$ [16].

Ууучшение показателей шкалы одышки по Боргу наблюдалось в группе риоцигуата к концу CHEST-1 $(-1,05 \pm 2,26 \quad(\mathrm{n}=154)$, что подАерживалось к 12-й недеме CHEST-2 (n=145) и к первому году мечения 
$[-0,80 \pm 2,41(\mathrm{n}=113)]$. Пациенты в бывшей группе плацебо показали начальные изменения уже в конце исслеАования CHEST-1 ( $\mathrm{n}=81)$, с Аальнейшим улучшением показателей после начала приема риоцигуата в исслеАовании CHEST-2 к 12-й неделе $(\mathrm{n}=75)$ и первому гоАу $-0,57 \pm 1,98(\mathrm{n}=58)[16,18,19]$. Бомее того, укучшение Аанных шкалы европейского опросника качества жизни наблюАалось в группе риоцигуата к концу CHEST-1 $(\mathrm{n}=154)$ и продолжалось в СНEST-2 к 12-й неделе $(\mathrm{n}=145)$ и первому году $(\mathrm{n}=113)$. В то же время пациенты из группы плацебо показали улучшение в течение исследования CHEST-1 ( $\mathrm{n}=81)$, но при этом продемонстрировали умеренную положительную Аинамику после начала приема риоцигуата в CHEST-2 к 12-й недеме $(\mathrm{n}=75)$ и первому году $(\mathrm{n}=58)$. Выживаемость больных к первому году наблюдения в исследовании CHEST-2 составика 97\% (93\% worst-case анализ), выживаемость пациентов без событий кАинического ухудшения составила $88 \%$ ( $86 \%$ worst-case анализ) [16].

К марту 2014 года 172 пациента находились на постоянном мечении риоцигуатом, 171 пациент принимал лечение более Авух мет в рамках исследования CHEST-1 и CHEST-2, и 18 пациентов переключились на коммерческий препарат. За время наблюдения только 6\% пациентов были исключены из исследования в связи с нежелательными явлениями (НЯ), что говорит о хорошей переносимости риоцигуата. В целом риоцигуат благоприятно переносился пациентами. Серьезные нежемательные явления (СНЯ) наблюдались у 129 из 327 больных (54\%). Ко второму году наблюдения в исслеАовании CHEST-2 по сравнению с исходными данными CHEST-1 наблюдалось (среднее \pm CO) увекичение AT6MX на $+50 \pm 68$ м $(\mathrm{n}=162)$. Ко второму году выживаемость составима 93\% [19].

Недавно был опубликован post-hoc анализ CHEST-1, в котором преАставлена Аетальная информация относительно изменения параметров гемодинамики у пациентов с неоперабельной ХТЭАГ и персистирующей/peцидивирующей $\Lambda \Gamma$ после $\Lambda$ ТЭЭ. Настоящая работа интересна тем, что в исходной публикации результатов CHEST-1 преАставлено меньше гемодинамических параметров, чем в Аанном post-hoc анализе. Улучшения гемодинамики межАу подгруппами «неоперабельная ХТЭ $\Lambda Г »$ и «персистирующая/ рецидивирующая $\Lambda \Gamma$ посме $\Lambda$ ТЭЭ» были сопоставимы. В общей попумяции пациентов была показана корремяция между улучшениями $\Lambda$ СС, сердечного индекса и увеличением АТ6МХ. Результаты данного post-hoc анализа еще раз подчеркивают благоприятный профиль эффективности риоцигуата, который быи показан в CHEST-1 [20].

В 2018 году был опубликован ретроспективный анализ исследований риоцигуата с анализом эхокардио- графических (ЭхоКГ) Аанных пациентов - RIVER [21]. Проводикась оценка размеров и функции правых отдемов сераца во время алительного применения риоцигуа-

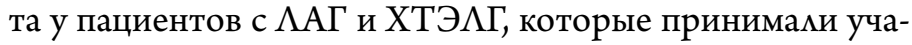
стие в проспективных, рандомизированных, Авойных слепых, многоцентровых, плацебо-контролируемых исследованиях с применением риоцигуата в парамлельных группах PATENT-1, PATENT plus, CHEST-1, исслеАовании II фазы, EAS и соответствующих пролонгированных исследованиях. ЭхоКГ оценка основных параметров проводилась исходно, через 3, 6, 12 месяцев. Первичной конечной точкой явимось изменение пмощади правого преАсердия через 12 месяцев цечения, по сравнению с исходным. КАинически значимое улучшение размеров правых отАелов сераца определяли, как уменьшение площаАи правого преАсердия или правого желудочка на $\geq 15 \%$. В исследовании RIVER были ретроспективно проанамизированы ЭхоКГ Аанные 71 пациента: 39 пациентов (55\%) с ХТЭАГ и 32 пациента (45\%) с $\Lambda$ АГ. В исследовании RIVER на фоне Алительного приема риоцигуата наблюдалось значительное уменьшение размеров правых отделов сердца У пациентов с $\Lambda$ АГ и ХТЭ $\Lambda Г$, что способствовало укучшению правожекудочковой функции [21].

В 2019 году были опубликованы результаты ретроспективного кАинического чешского регистра, гАе изучалось влияние терапии риоцигуатом на клинические параметры и качество жизни пациентов с неоперабельной ХТЭАГ или персистирующей / рецидивирующей ХТЭАГ после проведения $\Lambda$ ТЭЭ в Аолгосрочной перспективе в условиях реальной клинической практики. В исслеАование включен 51 пациент с неоперабельной ХТЭАГ ими персистирующей/рецидивирующей ХТЭ $\Lambda Г$ после $\Lambda$ ТЭЭ, которые начали мечение риоцигуатом примерно за гоА Ао включения в регистр. На фоне терапии риоцигуатом отмечались благоприятные эффекты у пациентов с неоперабельной ХТЭАГ или персистирующей/рециАивирующей ХТЭАГ после $\Lambda$ ТЭЭ в Аолгосрочной перспективе в условиях реальной клинической практики. ОАнолетняя выживаемость пациентов на фоне терапии риоцигуатом в реальных кминических условиях составима $89,1 \%$ [22].

Также быми опубликованы результаты исследования Аолгосрочной терапии риоцигуатом больных с неоперабельной и резидуальной ХТЭАГ. В Аанном исследовании проводилась оценка клинических и мабораторных показателей, анализировались время Ао метального исхоАа и время до развития клинического ухудшения состояния пациентов. Также преАпринята попытка определить предикторы иетального исхода и клинического ухудшения; проведено сравнение данных реальной клинической практики с рандомизированными клиническими исследованиями риоцигуата. Ретроспективный анализ 


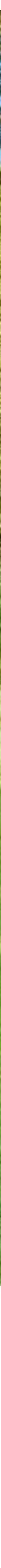

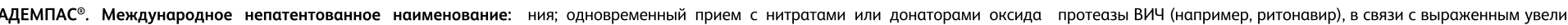

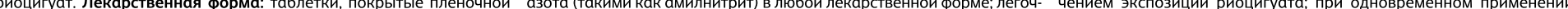

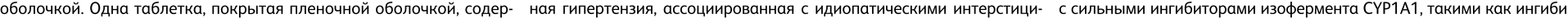
жит 0,50; 1,00; 1,50; 2,00 или 2,50 мг риоцигуата микронизированно- альными пневмониями (ЛГ-ИИП); возраст до 18 лет; врожденный го. Показания к применению: хроничесая тромбоэ оолиеская дефицит лактазы, непереносимость лактозы, глюкозо-галактозная го. Показ гиперте (ХТЭЛГ, группа 4 по классификачии ВОЗ): легочная гия к лечения взрослых пациентов при: неоперабельная ХТЭЛГ, персисти- артериальная типотензия на момент начала терапии (систоличес-

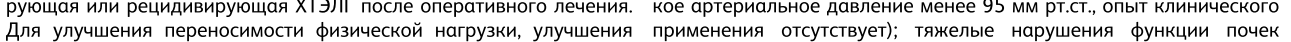
функционального класса по ВО3); легочная артериальная гипертен- (клиренс креатинина менее 15 мл/мин) и применение у пациентов, зия (ЛАГ), группа 1 по классификации ВОЗ: для лечения взрослых находящихся на гемодиализе (опыт клинического применения пациентов С ЛАГ для улучшения переносимости физической нагруз- отсутствует). С осторожностью: необходимо соблюдать дополники, функционального класса ВОЗ и задержки ния. II-III ФК по классификации ВОЗ (в монотерапии либо в комбинации с антагонистами рецепторов эндотелина или простаноидами): тельные факторы риска кровотечения из дыхательных путей, с болезнями соединительной ткани. Противопоказания: одновре- тов, получающих гипотензивную терапию или имеющих исходную менное применение с ингибиторами ФДЭ-5 (такими как силденафил, артериальную гипотензию, гиповолемию, либо тяжелую обструкцию тадалафил, варденафил); тяжелые нарушения функции печени путей оттока из левого желудочка или вегетативную дисфункцию; (класс С по классификации Чайлд По); пов ность к риоцигуату или любому другому компоненту, входящему в состав препарата; беременность и период грудного вскармлива- средства (например, кетоконазол, итраконазол) или ингибиторами ор тирозининазы эрлотиниб, и сильны ии ингибиторами Р-gP/BCRP, 5 мл/мин); у пациентов с умеренным нарушением функции печени (класс В по шкале Чайлд-Пью); у пациентов пожилого возраста (65 лет и старше). Побочное действие: очень часто-головокружение, оловная боль, диспепсия, диарея, тошнота, рвота, периферические отеки, часто - гастроэнтерит, анемия (включая соответствующие лабораторные показатели), учащенное сердцебиение, снижение артериального давления, кровохарканье, носовое кровотечение, заложенность носа, гастрит, гастроэзофагеальная рефлюксная болезн дисфагия, боль в разных отделах ЖКТ, запор, вздутие живота. Регистраи Опускается по рецепту врача. Подробная информация (включая информацию о способе применения и дозы) содержится в инструкпри одновременном применении с сильными ингибиторами изофер- информацию о способ 
Аанных 36 пациентов быи проведен с 2014 по 2019 гоА. Большая часть пациентов (92\%) имела неоперабельную форму ХТЭАГ. У всех пациентов исследования была инициирована терапия риоцигуатом, но в ряде случаев была возможна комбинация с транслюминальной бамлонной ангиопмастикой (БАП) $\Lambda$ А. СреАняя Алительность терапии риоцигуатом составила 2,3 гоАа, при этом большинство пациентов (83\%) получали риоцигуат в максимальной дозировке 2,5 мг 3 раза в сутки. Через 4 года общая выживаемость пациентов составила $80 \%$, а клинические ухудшения отмечалось только у 7 пациентов. Выживаемость без событий клинического ухудшения через 4 гоАа составила $63 \%$. Зафиксированные НЯ и СНЯ соответствовали известному профилю безопасности, более того, в когорте пациентов этого исследования отсутствовали такие СНЯ, как кровохарканье или мегочные кровотечения [23].

Амя изучения профимя безопасности риоцигуата в терапии ХТЭАГ было проведено наблюАательное исслеАование EXPERT. В регистр EXPERT вкмючали пациентов, которые начали мечение риоцигуатом, или которые уже получают мечение риоцигуатом. В анализ включено 956 пациентов. Причем примерно половина больных с ХТЭАГ, которые получали терапию риоцигуатом, имеми неоперабельною форму заболевания. Большинство пациентов (76\%) принимали риоцигуат в режиме монотерапии. Результаты анализа финальных Аанных регистра EXPERT показали, что зафиксированные НЯ и СНЯ соответствовали уже известному профилю безопасности риоцигуата. Также отмечается, что у пациентов, которые начали терапию риоцигуатом в течение менее 3 месяцев Ао включения в регистр, НЯ, связанные с приемом исслеАуемого препарата, отмечались ожидаемо чаще, чем у пациентов, которые получали мечение риоцигуатом $\geq 3$ месяцев до включения в регистр. Пациенты когорт «вновь назначенная терапия» и «преАварительное мечение риоцигуатом» характеризовались, в цемом, схожей частотой возникновения НЯ и СНЯ [24].

Известно, что у пациентов с ХТЭ $\Lambda Г$ во время физических нагрузок часто возникает гипоксия, которая существенно ограничивает физическую активность данной категории больных. Комлегами из Японии было провеАено исследование, в котором изучались эффекты риоцигуата относительно укучшения насыщения крови кислородом у больных с ХТЭАГ во время физических нагрузок. Было показано, что риоцигуат статистически значимо укучшил периферическую кислородную сатурацию во время физической нагрузки у изучаемых пациентов [25].

Важным методом обследования пациентов с ХТЭАГ является катетеризация правых отделов серАца (КПОС), проводимая с целью верификации диагноза, оценки тя- жести гемодинамических нарушений, решения вопроса о выборе и оценке эффективности терапии, определения прогноза. Аанных реальной клинической практики относительно эффектов риоцигуата на мегочную гемоАинамику мамо, особенно Амя азиатской попумяции. Учитывая количество пациентов и важность вопроса, было проведено ретроспективное исследование, целью которого явилось изучение влияния риоцигуата на мегочную гемодинамику у неоперабельных больных с ХТЭАГ азиатской попумяции. С января 2010 года по ноябрь 2018 года были проанализированы данные КПОС 11 пациентов с ХТЭАГ, покучавших риоцигуат, медиана проАолжительности мечения составила 12 месяцев. В качестве первичной конечной точки оценивали изменения параметров мегочной гемодинамики через 12 месяцев терапии риоцигуатом. На фоне терапии риоцигуатом было показано значимое укучшение ср $\Lambda \Lambda \mathrm{A}, \Lambda \mathrm{CC}$, а также NT-proBNP и ФК по ВОЗ у пациентов с неоперабельной ХТЭАГ. Несмотря на разные сроки наблюдения, улучшения срА $\Lambda$ А, сердечного выброса и $\Lambda$ СС в данном исследовании были схожи с результатами исслеАования CHEST-1 [26].

Представмяют интерес Аанные международного многоцентрового, неконтролируемого, ретроспективного исследования CAPTURE по изучению стратегии переключения с преАшествующей терапии на риоцигуат в рутинной клинической практике. $\Lambda$ АГспецифические препараты при недостаточной эффективности или неудовлетворительной переносимости часто заменяются на риоцигуат. В Аанном исследовании осуществлялся сбор Аанных пациентов с $\Lambda$ АГ или неоперабельной, или персистирующей / рецидивирующей ХТЭАГ, которые перешли на терапию риоцигуатом с Аругого препарата Амя мечения $\Lambda$ (NCT02545465). В исследование не включались пациенты, которые покучали риоцигуат в качестве дополнительной, комбинированной терапии в сочетании с антагонистами рецепторов эндотелина (АРЭ) или аналогами простациклина. Аанные, покученные на основании истории болезней, анализировались ретроспективно за периоА: 12 месяцев до смены терапии и спустя 5 месяцев. Исходно в исследовании 66\% пациентов находились в III ФК по ВОЗ, причем $68 \%$ пациентов были с Аиагнозом ХТЭАГ. СреАи пациентов с ХТЭ $\Lambda Г$ чаще всего в качестве преАшествующего мечения назначались ИФАЭ-5-43 пациента (52\%) и комбинация АРЭ с ИФАЭ-5 у 19 пациентов (23\%); 64 пациентов (78\%) сменили терапию с ИФАЭ-5 на риоцигуат. У $78 \%$ пациентов с ХТЭАГ был осуществлен перевоА с ИФАЭ-5. Наиболее частой причиной перевода ( $85 \%)$ пациентов с ХТЭАГ на риоцигуат была неэффективность предшествующей терапии. После смены терапии $71 \%$ пациентов с ХТЭАГ получали 
риоцигуат в режиме монотерапии, 22\% - в составе комбинированной терапии с АРЭ [27].

Результаты исследования CAPTURE показали, что смена неэффективной преАшествующей терапии на риоцигуат явцяется безопасной и хорошо переносится пациентами.

\section{Риоцигуат в сравнении с баммонной} ангиопмастикой мегочных артерий

Среди современных методов мечения пациентов с неоперабемьной ХТЭАГ особое место занимает БАП $\Lambda$, которая с 2015 г. Европейским обществом карАиологов введена в структуру алгоритма мечения ХТЭАГ с классом рекоменааций IIb, уровнем Аоказательств C [3]. БАП $\Lambda$ А представмяет собой эндоваскумярное вмешательство, при котором проводится поэтапная Аилатация пораженного сегмента $\Lambda$ А поА контромем ангиопумьмонографии. Решение о провеАении БАП $\Lambda$ п при ХТЭ $А Г$ принимается межАисципиинарной командой, включающей карАиохирурга, эндоваскуяярного хирурга и карАиолога. КанАиАатами Аля энАоваскулярного мечения являются пациенты с тромботическим Аистальным поражением сосудистого русла (на уровне сегментарных и субсегментарных ветвей $\Lambda$ A), пациенты с наличием резидуацьной $\Lambda$ после $\Lambda$ ЭЭЭ.

В скучае неэффективности патогенетической терапии иии невозможности ее назначения также возможно выпомнение БАП $\Lambda$ А. В практику уверенно вхоАит гибриАный поАхоА мечения неоперабельной ХТЭАГ, при котором оперативному мечению предшествует серия БАП $\Lambda$ А Ао необходимого Амя хирургического вмешательства улучшения гемодинамических показатемей. Есть немногочисленные Аанные, сравнивающие размичные методы мечения ХТЭАГ, в частности сравнивающие эффективность применения риоцигуата и БАП $\Lambda$ А.

Так, осенью 2019 года на Европейском респираторном конгрессе в Мадриде были преАставлены первые Аанные многоцентрового рандомизированного контромируемого исследования RACE, в котором оценивалась эффективность и безопасность риоцигуата по сравнению с БАП $\Lambda$ А у вновь Аиагностированных и не получавших мечения пациентов с неоперабельной ХТЭАГ. В период с января 2016 года по январь 2019 года 105 пациентов с I-IV ФК (ВО3) с $\Lambda$ CC >320 Аин $\times$ схсм ${ }^{-5}$, были рандомизированы в соотношении 1:1 Аля мечения риоцигуатом ими Аля проведения БАП $\Lambda$ А. Первичной конечной точкой было изменение $\Lambda$ СС к 26-й неделе. Вторичные конечные точки вкмючали изменения АТ6МХ, ФК (BO3), NT-proBNP, время Ао клинического ухуАшения и безопасность. На сегоАняшний Аень уже Аоступны промежуточные резумьтаты, при этом помный от- чет о результатах исследования ожидается в 2020 году $[28,29]$.

\section{Опыт применения риоцигуата}

при ХТЭАГ в Научно-исслеАовательском институте кАинической карАиологии им.А. А. Мясникова ФГБУ «НМИЦ карАиологии Минзарава России

Опыт применения риоцигуата в НИИ кминической карАиологии им. А. $\Lambda$. Мясникова ФГБУ «НМИЦ карАиологии» Минзарава России, основанный на анализе результатов российского регистра (NCT03707561) показывает, что риоцигуат назначается примерно у трети больных с ХТЭАГ с Аостижением максимацьной Аозы 7,5 мг в сутки у $62 \%$ пациентов. $60 \%$ больных получают сицденафиц, что можно объяснить Аоступностью генерических форм [30]. Важно подчеркнуть, что Аля пациентов с ХТЭАГ терапия ИФАЭ-5 Ао настоящего времени остается «off-label», в связи с этим накапиивается опыт по изучению стратегии переключения симденафима на риоцигуат у Аанной категории больных. По нашим Аанным, у 55\% больных к 6-13 мес. от начала мечения симденафилом удается осуществить эффективную оптимизацию мечения с заменой препарата на риоцигуат.

На основании Аанных регистра была проведена оценка бремени ХТЭАГ в Российской ФеАерации. Бомьшинство пациентов (55\%) находились в трудоспособном возрасте. Бомее $70 \%$ пациентов на момент установмения Аиагноза быми в III и IV ФК по ВОЗ. Общие среАние затраты на оАного пациента в гоА составили 805901 [АИ: 988294; 1037049] руб., при этом прямые затраты составики $91 \%$, а непрямые - 9\% от общей суммы расходов. При анализе потребления $\Lambda$ АГ-специфических препаратов выявмены Алитемьные перерывы в связи с проблемами мекарственного обеспечения пациентов с ХТЭАГ [31].

По нашим Аанным, выживаемость пациентов с ХТЭАГ за год наблюдения составима 98\%, 96\% за 3 года и 93\% - за 5 мет [30]. Эти результаты согласуются с недавно опубликованной работой по оценке эффективности риоцигуата в реальной кминической практике у пациентов с неоперабемьной и резидуамьной ХТЭАГ: 3-летняя выживаемость при ХТЭАГ в реальных клинических условиях составила 94\%; выживаемость без событий клинического ухуАшения - 78\% [23].

\section{Закмючение}

В настоящее время «золотым стандартом» мечения пациентов с ХТЭАГ остается $\Lambda$ ТЭЭ. Несмотря на то, что оперативное мечение, выполняемое в условиях центров с передовым опытом, в целом демонстрирует хо- 
рошие результаты, Ао 40\% пациентов являются технически неоперабельными ими $\Lambda$ ТЭЭ сопряжена с высоким риском осложнений. ВнеАрение стимулятора рГЦ риоцигуата в клиническую практику можно назвать настоящим прорывом в мечении пациентов с ХТЭАГ, которым невозможно провести $\Lambda$ ТЭЭ или у которых после оперативного мечения наблюАается рецидив или персистирующая ХТЭАГ. Появмение этого инновационного пре- парата, обладающего уникальным Авойным механизмом Аействия, открывает новые перспективы патогенетической терапии пациентов с ХТЭАГ.

\section{Раскрытие интересов: статьл при поддержке

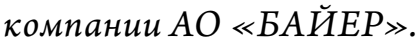

Статья поступима 24.05.2020

\section{СПИСОК АИТЕРАТУРЫ}

1. Condliffe R, Kiely DG, Gibbs JSR, Corris PA, Peacock AJ, Jenkins DP et al. Improved Outcomes in Medically and Surgically Treated Chronic Thromboembolic Pulmonary Hypertension. American Journal of Respiratory and Critical Care Medicine. 2008;177 (10):1122-7. DOI: $10.1164 / \mathrm{rccm} .200712-18410 \mathrm{C}$

2. Chazova I. E., Martynyuk T. V., Filippov E. V. Clinical guidelines for the diagnosis and treatment of chronic thromboembolic pulmonary hypertension (Part 1). Therapeutic Archive. 2016;88 (9):90-101. [Russian: Чазова И.Е., Мартынюк Т. В., Филиппов Е.В. Клинические рекомендации по диагностике и мечению хронической тромбоэмболической мегочной гипертензии (1 часть). Терапевтический архив. 2016;88 (9):90101]. DOI: $10.17116 /$ terarkh201688990-101

3. Galiè N, Humbert M, Vachiery J-L, Gibbs S, Lang I, Torbicki A et al. 2015 ESC/ERS Guidelines for the diagnosis and treatment of pulmonary hypertension: The Joint Task Force for the Diagnosis and Treatment of Pulmonary Hypertension of the European Society of Cardiology (ESC) and the European Respiratory Society (ERS): Endorsed by: Association for European Paediatric and Congenital Cardiology (AEPC), International Society for Heart and Lung Transplantation (ISHLT). European Heart Journal. 2016;37 (1):67-119. DOI: 10.1093 /eurheartj/ehv317

4. Chazova I.E., Martynyuk T. V., Valieva Z. S., Azizov V.A., Barbarash O. L., Veselova T.N. et al. Eurasian clinical guidelines on diagnosis and treatment of pulmonary hypertension. Eurasian Cardiology Journal. 2020;1 (30):78-122. [Russian: Чазова И.Е., Мартынюк Т. В., Валиева 3. С., Азизов В.А., Барбараш О. А., Веселова Т.Н. и Ар. Евразийские клинические рекоменАации по Аиагностике и мечению кегочной гипертензии. Евразийский кардиомогический журнал. 2020;1 (30):78-122]. DOI: 10.24411/2076-4766-2020-10002

5. Fernandes T, Auger W, Fedullo P. Epidemiology and risk factors for chronic thromboembolic pulmonary hypertension. Thrombosis Research. 2018;164:145-9. DOI: 10.1016/j.thromres.2018.01.012

6. Pepke-Zaba J, Jansa P, Kim NH, Naeije R, Simonneau G. Chronic thromboembolic pulmonary hypertension: role of medical therapy. European Respiratory Journal. 2013;41 (4):985-90. DOI: $10.1183 / 09031936.00201612$

7. Gall H, Hoeper MM, Richter MJ, Cacheris W, Hinzmann B, Mayer E. An epidemiological analysis of the burden of chronic thromboembolic pulmonary hypertension in the USA, Europe and Japan. European Respiratory Review. 2017;26 (143):160121. DOI: $10.1183 / 16000617.0121-2016$

8. Wilkens H, Konstantinides S, Lang IM, Bunck AC, Gerges M, Gerhardt $\mathrm{F}$ et al. Chronic thromboembolic pulmonary hypertension (CTEPH): Updated Recommendations from the Cologne Consensus Conference 2018. International Journal of Cardiology. 2018; 272:6978. DOI: $10.1016 /$ j.ijcard.2018.08.079

9. Pepke-Zaba J, Delcroix M, Lang I, Mayer E, Jansa P, Ambroz D et al. Chronic Thromboembolic Pulmonary Hypertension (CTEPH): Results from an International Prospective Registry. Circulation. 2011;124 (18):1973-81. DOI: 10.1161/CIRCULATIONAHA.110.015008

10. Cannon JE, Su L, Kiely DG, Page K, Toshner M, Swietlik E et al. Dynamic Risk Stratification of Patient Long-Term Outcome After Pulmo- nary Endarterectomy: Results from the United Kingdom National Cohort. Circulation. 2016;133 (18):1761-71. DOI: 10.1161/CIRCULATIONAHA.115.019470

11. Schermuly RT, Stasch J-P, Pullamsetti SS, Middendorff R, Muller D, Schluter K-D et al. Expression and function of soluble guanylate cyclase in pulmonary arterial hypertension. European Respiratory Journal. 2008;32 (4):881-91. DOI: 10.1183/09031936.00114407

12. Stasch J-P, Pacher P, Evgenov OV. Soluble Guanylate Cyclase as an Emerging Therapeutic Target in Cardiopulmonary Disease. Circulation. 2011;123 (20):2263-73. DOI: 10.1161/CIRCULATIONAHA.110.981738

13. State Register of Medicines. Instructions for medical use of drug Adempas. Av. at: https:// grls.rosminzdrav.ru/Grls_View_v2.aspx?routingGuid=bcc1261c9c93-4a15-ada6-b72604f247fd\&t=. [Russian: Государственный реестр мекарственных среАств. Инструкция по меАицинскому применению препарата ААемпас. Аоступно на: https:// grls.rosminzdrav.ru/Grls_View_v2.aspx?routingGuid=bcc1261c9c93-4a15-ada6-b72604f247fd\&t $=$ ]

14. Ghofrani HA, Hoeper MM, Halank M, Meyer FJ, Staehler G, Behr J et al. Riociguat for chronic thromboembolic pulmonary hypertension and pulmonary arterial hypertension: a phase II study. European Respiratory Journal. 2010;36 (4):792-9. DOI: 10.1183/09031936.00182909

15. Ghofrani H-A, D’Armini AM, Grimminger F, Hoeper MM, Jansa P, Kim NH et al. Riociguat for the Treatment of Chronic Thromboembolic Pulmonary Hypertension. New England Journal of Medicine. 2013;369 (4):319-29. DOI: 10.1056/NEJMoa1209657

16. Simonneau G, D’Armini AM, Ghofrani H-A, Grimminger F, Hoeper MM, Jansa $P$ et al. Riociguat for the treatment of chronic thromboembolic pulmonary hypertension: a long-term extension study (CHEST-2). European Respiratory Journal. 2015;45 (5):1293-302. DOI: $10.1183 / 09031936.00087114$

17. Mc Laughlin, V.V., Jansa, P., Nielsen-Kudsk, J.E. et al. Riociguat in patients with chronic thromboembolic pulmonary hypertension: results from an early access study. BMC Pulm Med 17, 216 (2017). https:// doi.org/10.1186/s12890-017-0563-7

18. Hoeper MM, McLaughlin VV, Dalaan AMA, Satoh T, Galiè N. Treatment of pulmonary hypertension. The Lancet Respiratory Medicine. 2016;4 (4):323-36. DOI: 10.1016/S2213-2600 (15) 00542-1

19. Simonneau G, D’Armini AM, Ghofrani H-A, Grimminger F, Jansa P, $\mathrm{Kim} \mathrm{NH}$ et al. Predictors of long-term outcomes in patients treated with riociguat for chronic thromboembolic pulmonary hypertension: data from the CHEST-2 open-label, randomised, long-term extension trial. The Lancet Respiratory Medicine. 2016;4 (5):372-80. DOI: $10.1016 /$ S2213-2600 (16) 30022-4

20. Kim NH, D’Armini AM, Grimminger F, Grünig E, Hoeper MM, Jansa $\mathrm{P}$ et al. Haemodynamic effects of riociguat in inoperable/recurrent chronic thromboembolic pulmonary hypertension. Heart. 2017;103 (8):599-606. DOI: 10.1136/heartjnl-2016-309621

21. Marra AM, Halank M, Benjamin N, Bossone E, Cittadini A, Eichstaedt $\mathrm{CA}$ et al. Right ventricular size and function under riociguat in pulmonary arterial hypertension and chronic thromboembolic pulmonary hypertension (the RIVER study). Respiratory Research. 2018;19 (1):258. DOI: 10.1186/s12931-018-0957-y 
22. Jansa P, Ambroz D, Kuchar J, Dytrych V, Lindner J, Linhart A. The im pact of riociguat on clinical parameters and quality of life in patients with chronic thromboembolic pulmonary hypertension - results of a retrospective clinical registry. Biomedical Papers. 2020; [Epub ahead of print]. DOI: $10.5507 /$ bp.2019.061

23. van Thor MCJ, ten Klooster L, Snijder RJ, Post MC, Mager JJ. Longterm clinical value and outcome of riociguat in chronic thromboembolic pulmonary hypertension. IJC Heart \& Vasculature. 2019; 22:163-8. DOI: $10.1016 /$ j.ijcha.2019.02.004

24. Ghofrani H-A, Gall H, Grünig E, Klose H, Halank M, Langleben $\mathrm{D}$ et al. Safety of Riociguat for the Treatment of Chronic Thromboembolic Pulmonary Hypertension: Final Data Cut from the EXPERT Registry. American Journal of Respiratory and Critical Care Medicine. 2019;199: A6067. [Av. at: https:// www.atsjournals.org/doi/10.1164/ajrccm-conference.2019.199.1_ MeetingAbstracts.A6067]. DOI: 10.1164/ajrccm-conference.2019.199.1 MeetingAbstracts.A6067

25. Hatano M, Maki H, Inaba T, Minatsuki S, Komuro I. Significant Improvement Of Oxygen Saturation Of Peripheral Artery During Exercise In Patients With CTeph Treated With Riociguat. American Journal of Respiratory and Critical Care Medicine. 2016;193: A5654. [Available at: https://www.atsjournals.org/doi/abs/10.1164/ajrccm-conference.2016.193.1_MeetingAbstracts.A5654]

26. Tsai C-H, Wu C-K, Kuo P-H, Hsu H-H, Chen Z-W, Hwang J-J et al. Riociguat Improves Pulmonary Hemodynamics in Patients with Inoperable Chronic Thromboembolic Pulmonary Hypertension. Acta Cardiologica Sinica. 2020;36 (1):64-71. DOI: 10.6515/ACS.202001_36 (1).20190612A

27. Gall H, Vachiéry J-L, Tanabe N, Halank M, Orozco-Levi M, Mielniczuk L et al. Real-World Switching to Riociguat: Management and Practicalities in Patients with PAH and CTEPH. Lung. 2018;196 (3):305-12. DOI: $10.1007 /$ s00408-018-0100-3
28. Riociguat Versus Balloon Pulmonary Angioplasty in Non-operable Chronic thromboEmbolic Pulmonary Hypertension (RACE). ClinicalTrials.gov Identifier: NCT02634203. [Internet] Available at: https://clinicaltrials.gov/ct2/show/NCT02634203

29. Jais $\mathrm{X}$, Brenot $\mathrm{P}$, Bouvaist $\mathrm{H}$, Canuet $\mathrm{M}$, Chabanne $\mathrm{C}$, Chaouat $\mathrm{A}$ et al. Late Breaking Abstract - Balloon pulmonary angioplasty versus riociguat for the treatment of inoperable chronic thromboembolic pulmonary hypertension: results from the randomised controlled RACE study. European Respiratory Journal. 2019;54 (Suppl 63): RCT1885. 2019. [DOI: 10.1183/13993003.congress-2019. RCT1885]

30. Chazova I. E., Valieva Z. S., Nakonechnikov S. N., Taran I. N., Martynyuk T. V. Features of clinical, functional and hemodynamics profile, medical treatment and prognosis evaluation in patients with inoperable chronic thromboembolic pulmonary hypertension and idiopathic pulmonary arterial hypertension according to the Russian registry. Therapeutic Archive. 2019;91 (9):7787. [Russian: Чазова И.Е., Валиева 3. С., Наконечников С. Н., Таран И. Н., Мартынюк Т. В. Особенности клиникофункционального и гемодинамического профимя, мекарственной терапии и оценка прогноза у пациентов с неоперабельной хронической тромбоэмболической и иАиопатической мегочной гипертензией по Аанным Российского регистра. Терапевтический архив. 2019;91 (9):77-87]. DOI: 10.26442/00403660.2019.09.000343

31. Chazova I.E., Martynyuk T.V., Valieva Z. S., Nakonechnikov S. N., Nedogoda S. V., Salasyuk A.S. et al. The economic burden of chronic thromboembolic pulmonary hypertension in Russian Federation. Therapeutic Archive. 2018;90 (9):101-9. [Russian: Чазова И.Е., Мартынюк Т.В., Валиева 3. С., Наконечников С.Н., Недогода С. В., Саласюк А. С. и Ар. Оценка бремени хронической тромбоэмболической мегочной гипертензии в Российской Федерации. Терапевтический архив. 2018;90 (9):101-9]. DOI: 10.26442/terarkh2018909101-109 